Article

\title{
Propagation from Basal Epicormic Meristems Remediates an Aging-Related Disorder in Almond Clones
}

\author{
Thomas Gradziel ${ }^{1, *}$, Bruce Lampinen ${ }^{1}$ and John E. Preece ${ }^{2}$ \\ 1 Department of Plant sciences, University of California, Davis, CA 95616, USA; bdlampinen@ucdavis.edu \\ 2 USDA/ARS Germplasm Repository, Davis, CA 95616, USA; john.preece@ars.usda.gov \\ * Correspondence: tmgradziel@ucdavis.edu; Tel.: +1-530-752-1575
}

Received: 5 February 2019; Accepted: 7 April 2019; Published: 11 April 2019

check for updates

\begin{abstract}
The asexual propagation of clonal crops has allowed cultivation of superior selections for thousands of years. With time, some clones deteriorate from genetic and epigenetic changes. Non-infectious bud-failure (NBF) in cultivated almond (Prunus dulcis) is a commercially important age-related disorder that results in the failure of new vegetative buds to grow in the spring, with dieback of terminal shoots, witches-brooming of surviving buds, and deformed bark (roughbark). The incidence of NBF increases with clone age, including within individual long-lived trees as well as nursery propagation lineages. It is not associated with any infectious disease agents. Consequently, nursery practices emphasize the establishment of foundation-mother blocks utilizing propagation-wood selected from proven and well-monitored propagation-lineages. Commercial propagation utilizes axillary shoot buds through traditional budding or grafting. This study examines NBF development using basal epicormic buds from individual trees of advanced age as an alternative source of foundation stock. Results show the age-related progression of NBF is suppressed in these epicormic meristems, possibly owing to their unique origins and ontogeny. NBF development in commercial orchards propagated from foundation blocks established from these sources was similarly dramatically suppressed even over the 10- to 20-year expected commercial orchard-life. Foundation-stock stability can be further maintained through appropriate management of propagation source-trees, which requires accurate knowledge of meristem origin and development.
\end{abstract}

Keywords: clone aging; foundation-stock; genetic-disorder; non-infectious; epigenetic

\section{Introduction}

Vegetative propagation allows the capture and immortalization of horticulturally desirable genetic/genomic configurations with the estimated age of some vegetatively propagated fig and grape clones at over 1000 years [1]. The deterioration of clone performance with age has similarly been reported in several crops [2-4] due to genetic [4] or epigenetic $[5,6]$ changes resulting in losses in productivity and/or crop value. Non-infectious bud-failure (NBF) is a disorder of almond (Prunus dulcis, DA Webb) characterized by the failure of terminal vegetative buds to push in the spring [7]. Because new shoot and branch development is necessary in almond to produce new flowers and fruit-bearing wood, NBF development often results in a dramatic loss of crop productivity, particularly when occurring early in orchard tree structural development [8]. Once established, it is irreversible [9] with expression becoming more extensive with increasing time both in individual affected trees as well as in nursery propagation-lineages. Most tree crop nurseries maintain distinct propagation-lineages (i.e., clonal propagation sources that can be traced back through earlier propagations to a common source) to preserve the integrity and quality of their clones. To ensure availability of propagation material 
that is true-to-type and free from virus-infection and genetic disorders, commercially important clonal propagation sources are maintained in special foundation blocks which are quarantined to control virus contamination and routinely monitored for quality maintenance. Foundation propagation stock from these blocks is then used to establish commercial nursery 'mother-blocks' which, in turn, provide the quality and quantity of buds required for commercial plantings. NBF was first reported in California almond orchards in the early 1930s [10], and has resulted in the commercial decline of many otherwise valuable cultivars and currently threatens the commercial viability of Nonpareil and Carmel, the two most extensively planted California cultivars [8]. Nonpareil, the dominant commercial cultivar, currently at 162,000 ha [11], was originally released in the 1860s with NBF first reported about 1930 [10]. Carmel, the second most important commercial cultivar with current plantings of approximately 53,000 ha was released in 1964 with NBF first being observed in 1978 [12]. Extensive research has failed to find any association of NBF with known pathogens, including viruses and viroids [13-17]. A comprehensive evaluation of nursery foundation stock for the highly NBF vulnerable cultivar Carmel demonstrated lower incidence in orchards propagated from 'relic-trees' (i.e., trees closely related by their propagation lineage to the original Carmel seedling tree) [18]. Consequently, most current nursery production of both Carmel as well as Nonpareil are based on foundation-stock originating from epicormic shoots developing at the base of 50 to 100 year-old 'relic' trees of Carmel and Nonpareil, respectively. Epicormic shoots in almond are defined as neoformed shoots that are produced from latent meristems that have remained dormant until a signal causes them to grow [19]. They differ from the axillary buds used in traditional propagations in their origins and development, having similarities with the better-studied epicormic growth in oaks [20,21].

Epicormic shoots appear to originate as axillary and associated subtending meristems that initially did not grow and became covered with bark [22]. Thus, the ontological developmental phase at the time of the formation is captured. In Quercus rubra, when the main stem (trunk) of trees was cut into $40 \mathrm{~cm}$ segments and green shoots forced, they rooted differentially from a rate of $70 \%$ for the bottom and most basal segment to $17 \%$ on segments cut from 3-4 $\mathrm{m}$ above ground [23] demonstrating that the oldest epicormic buds can be quite different in their ontogeny and subsequent development than younger buds. The increase in NBF expression potential with increasing tree and clone age may thus be similar to epicormic meristem development in the better-studied forest tree species. This study examines long-term NBF development when using basal epicormic buds from individual trees of advanced age rather than traditional axillary buds as the propagation source.

\section{Materials and Methods}

Standard commercial propagation sources (source-clones) for the varieties Carmel and Nonpareil were compared against propagation sources from relic-tree basal epicormic origins (REO). Carmel and Nonpareil test trees were planted in alternate rows with pollinizer trees to provide cross-pollination. All trees were propagated on Nemaguard rootstock using traditional T-budding of axillary buds from previous season's growth of propagation source trees. Source-clone mother trees were either from traditional nursery propagation lineages or one to two generations removed from a REO source (Tables 1 and 2). For Carmel, at least 180 trees per source-clone as well as 31 trees propagated from the original Carmel seedling tree were evaluated. For Nonpareil, 60 trees of each source-clone were tested. Planting took place in 1990 near Wasco, California in the southern San Joaquin Valley where high summer temperatures have been shown to be conducive to early NBF development [18]. Planting was carried out in randomized groups of 10 trees each, in north-south rows with a $7.3 \times 6.4 \mathrm{~m}$ spacing on a Wasco-Sandy-loam soil. Standard orchard management practices were applied to all treatments.

Four Carmel REO source-clones were evaluated. One tree (subsequently designated as the Delta mother tree) was propagated from basal buds of the original Carmel seedling tree with 3 trees subsequently propagated from this Delta mother tree (Foundation Plant Services (FPS) sources 3-56-1-90, 3-56-8-92 and 3-56-2-90) (Table 2). Four standard commercial propagation sources (C1-C4) of Carmel 
were provided by cooperating nurseries as part of a larger evaluation of NBF risk in commercially available California propagation stocks [18].

Table 1. Carmel almond propagation sources.

\begin{tabular}{ccc}
\hline Source & FPS ID $^{\mathbf{1}}$ & Origin \\
\hline E1 & na & Delta-mother tree propagated from original Carmel seedling tree \\
E2 & $3-56-1-90$ & Delta source tree 2 propagated basal epicormic bud from Delta tree \\
E3 & $3-56-8-92$ & Delta source tree 13 propagated basal epicormic bud from Delta tree \\
E4 & $3-56-2-90$ & Delta source tree 7 propagated basal epicormic bud from Delta tree \\
C1 & na & Standard commercial nursery source established in 1988 \\
C2 & na & Standard commercial nursery source established in 1986 \\
C3 & na & Standard commercial nursery source established in 1985 \\
C4 & na & Standard commercial nursery source established in 1981 \\
\hline
\end{tabular}

${ }^{1}$ last 2 digits of Foundation Plant Services identification number (FPS ID) denote year of establishment.

Table 2. Nonpareil almond propagation sources.

\begin{tabular}{ccc}
\hline Source & FPS ID $^{\mathbf{1}}$ & Origin \\
\hline E1 & $3-8-6-72$ & Propagated from a basal epicormic bud of a 108-year-old relic tree \\
E2 & $3-8-17-92$ & Propagated from a basal epicormic bud of a 100+ year-old relic tree \\
E3 & $3-8-2-70$ & Propagated from a basal epicormic bud of a 100+ year-old heat-treated relic tree \\
E4 & na & Commercial nursery propagation source originating from 100+ year-old relic tree \\
C1 & na & Standard commercial nursery source established in 1988 \\
C2 & na & Standard commercial nursery source established in 1986 \\
C3 & na & Standard commercial nursery source established in 1984 \\
C4 & na & Standard commercial nursery source established in 1977 \\
\hline
\end{tabular}

${ }^{1}$ last 2 digits of Foundation Plant Services identification number (FPS ID) denote year of establishment.

Four REO source-clones for Nonpareil were derived from 100+ year old trees from orchards in the cooler northern Sacramento Valley (Table 1). Adventitious epicormic shoots either spontaneously pushing from intact trees or artificially pushed by partial tree girdling/scaffold removal (Figure 1) were used to establish three source-clones (3-8-6-72, 3-8-17-92 and 3-8-2-70) at the University of California FPS Foundation Orchard [24]. An additional REO source designated (E3) was developed by a cooperating commercial nursery. Four standard commercial propagation sources (C1-C4) of Nonpareil were provided by cooperating nurseries as part of a larger evaluation of NBF risk in commercially available California propagation stock [18].

Trees were evaluated using established ratings for NBF expression [18] over the next 18 years or until plot removal due to excessive tree decline and loss of commercial productivity. Trees were evaluated in March following primary shoot development. Initial NBF incidence was identified as a failure of terminal shoot bud growth resulting in the induction and growth of sub-apical buds resulting in a distinct terminal shoot die-back as shown in 'a' of Figure 2. Once identified, NBF was verified in subsequent years by a consecutive pattern of terminal shoot failures (as in ' $b$ ', ' $c$ ', and 'd' in Figure 2) resulting in the distinct 'crazy-top' growth pattern characteristic of NBF. 


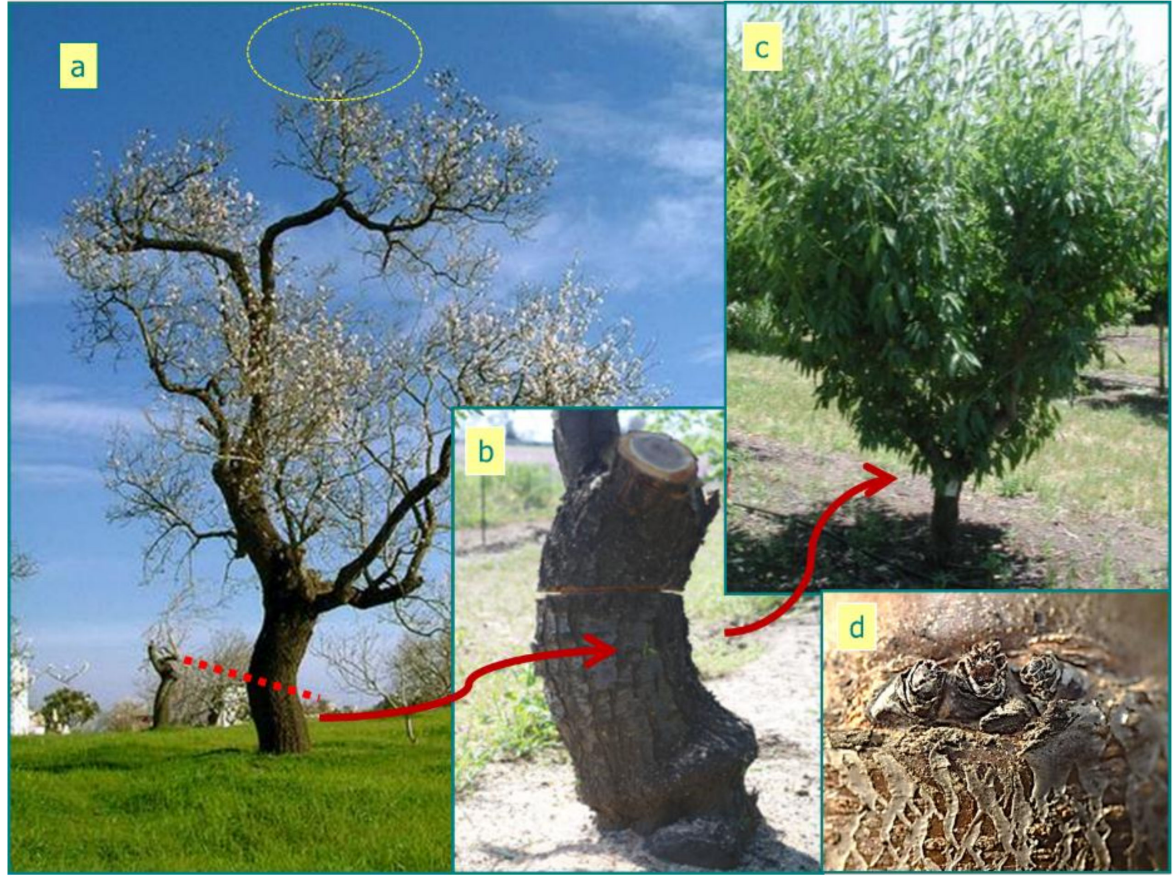

Figure 1. Low non-infectious bud-failure (NBF) foundation stock is developed from epicormic buds (b,d) pushed from relic trees (planted near the time of cultivar origin) (a). Resulting foundation stock (c) is maintained by aggressive annual pruning to promote both axillary and epicormic shoot growth from older basal wood. (Circled top branch in (a) shows classic NBF symptoms of terminal shoot suppression and resulting erratic branching patterns).

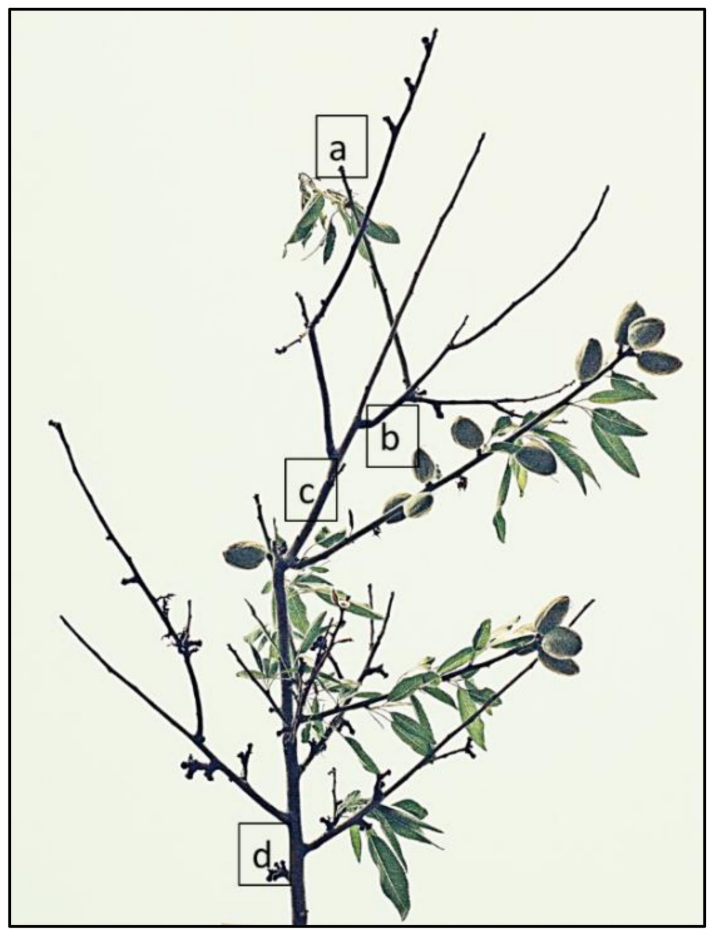

Figure 2. Shoot expression of NBF. Terminal vegetative buds fail to grow shifting growth to a sub-apical bud (a). The pattern is repeated here with three previous seasons' shoot growth-failures (b, $c$, and d, respectively) present, resulting in a distinct pattern known as 'crazy-top'. Note that flower buds are not directly affected. 


\section{Results}

\subsection{Carmel}

All FPS REO clone-sources showed no occurrence of NBF until year 8 of the study (Table 3). In contrast, all commercial sources showed NBF by year 4 with commercial clone-source C 4 showing almost $100 \%$ of trees affected at this time. The clone-source $C 4$ was also the oldest traditional commercial source-clone tested, having been established in 1981. FPS REO clone-source E4 went from 0\% to 51\% incidence in year 7 , rapidly increasing to almost $89 \%$ by year 10 , the last year before orchard removal due to loss of commercial productivity (Figure 3). The remaining FPS REO clone-sources E1, E2 and E3 showed NBF expression of only $3 \%, 5 \%$ and $11 \%$, respectively, at year 8 , with a gradual increase in incidence to $13 \%, 8 \%$ and $15 \%$, respectively, by year 10 .

Table 3. Development of NBF over a 10 year of evaluation period for Carmel relic-tree basal epicormic origins (REO) source-clAones E1-E4 compared with standard commercial sources C1-C4.

\begin{tabular}{|c|c|c|c|c|c|c|c|c|c|c|c|c|c|c|c|c|}
\hline \multirow[b]{2}{*}{ Year } & \multicolumn{2}{|c|}{ E1 } & \multicolumn{2}{|c|}{ E2 } & \multicolumn{2}{|c|}{ E3 } & \multicolumn{2}{|c|}{ E4 } & \multicolumn{2}{|c|}{$\mathrm{C} 1$} & \multicolumn{2}{|c|}{ C2 } & \multicolumn{2}{|c|}{ C3 } & \multicolumn{2}{|c|}{$\mathrm{C} 4$} \\
\hline & $\begin{array}{c}\text { Bf } \\
\text { Trees }\end{array}$ & Per-cent & $\begin{array}{c}\text { Bf } \\
\text { Trees }\end{array}$ & Per-cent & $\begin{array}{c}\text { Bf } \\
\text { Trees }\end{array}$ & Per-cent & $\begin{array}{c}\text { Bf } \\
\text { Trees }\end{array}$ & Per-cent & $\begin{array}{c}\text { Bf } \\
\text { Trees }\end{array}$ & Per-cent & $\begin{array}{c}\text { Bf } \\
\text { Trees }\end{array}$ & Per-cent & $\begin{array}{c}\text { Bf } \\
\text { Trees }\end{array}$ & Per-cent & $\begin{array}{c}\text { Bf } \\
\text { Trees }\end{array}$ & Per-cent \\
\hline 1 & 0 & 0 & 0 & 0 & 0 & 0 & 0 & 0 & 0 & 0 & 0 & 0 & 0 & 0 & 0 & 0 \\
\hline 3 & 0 & 0 & 0 & 0 & 0 & 0 & 0 & 0 & 0 & 0 & 0 & 0 & 36 & 12.4 & 147 & 77.8 \\
\hline 4 & 0 & 0 & 0 & 0 & 0 & 0 & 0 & 0 & 60 & 14.7 & 53 & 22.5 & 102 & 35.1 & 183 & 96.8 \\
\hline 5 & 0 & 0 & 0 & 0 & 0 & 0 & 0 & 0 & 71 & 17.4 & 66 & 28.0 & 114 & 39.2 & 189 & 100 \\
\hline 6 & 0 & 0 & 0 & 0 & 0 & 0 & 0 & 0 & 114 & 28.0 & 102 & 43.2 & 156 & 53.6 & 189 & 100 \\
\hline 9 & 2 & 6.5 & 15 & 6.9 & 31 & 13.2 & 238 & 80.1 & 197 & 48.4 & 229 & 97.0 & 286 & 98.3 & 189 & 100 \\
\hline 10 & 4 & 12.9 & 17 & 7.8 & 34 & 14.5 & 264 & 88.9 & 213 & 52.3 & 236 & 100 & 291 & 100 & 189 & 100 \\
\hline Total & 31 & & 217 & & 234 & & 297 & & 407 & & 236 & & 291 & & 189 & \\
\hline
\end{tabular}

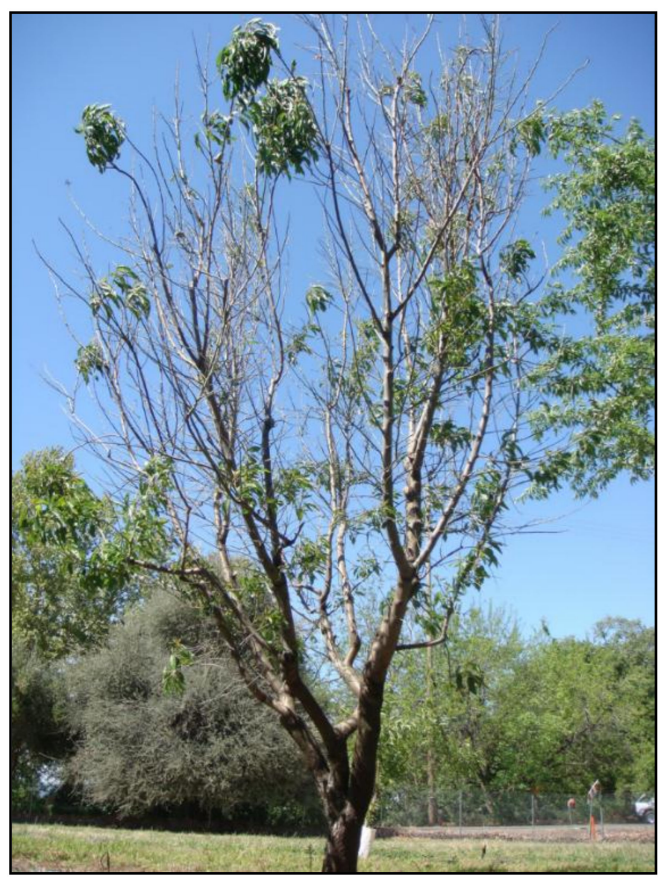

Figure 3. NBF expression in a nine-year-old tree where NBF was first observed in year 5, resulting in abnormal tree growth and loss of commercial productivity.

\subsection{Nonpareil}

Complete control of NBF was achieved in all FPS REO clone sources over the 18-year trial (Table 4). In the commercially developed REO source E4, 5\% of trees showed NBF symptoms by year 18, the final year before orchard removal. All commercial sources showed NBF by year 10, with incidents ranging from $2 \%$ to $22 \%$. Final, year 18 , incidence of NBF in commercial sources ranged from $35 \%$ to $87 \%$. 
Commercial clone-source C4, which showed the highest NBF incidents and rate of increase, was also the oldest traditional commercial source-clone tested, having been established in 1977.

Table 4. Development of NBF over an 18-year evaluation period for Nonpareil REO source-clones E1-E4 compared with standard commercial sources C1-C4. (Sixty trees of each clone-source were evaluated).

\begin{tabular}{|c|c|c|c|c|c|c|c|c|c|c|c|c|c|c|c|c|}
\hline \multirow[b]{2}{*}{ Year } & \multicolumn{2}{|c|}{$\underline{\mathrm{E} 1}$} & \multicolumn{2}{|c|}{$\underline{\mathrm{E} 2}$} & \multicolumn{2}{|c|}{$\underline{\mathrm{E} 3}$} & \multicolumn{2}{|c|}{$\underline{\mathrm{E} 4}$} & \multicolumn{2}{|c|}{$\underline{\mathrm{C} 1}$} & \multicolumn{2}{|c|}{$\underline{\mathrm{C} 2}$} & \multicolumn{2}{|c|}{$\underline{\mathrm{C} 3}$} & \multicolumn{2}{|c|}{$\underline{\mathrm{C} 4}$} \\
\hline & $\begin{array}{c}\text { BF } \\
\text { Trees }\end{array}$ & Per-cent & $\begin{array}{c}\text { BF } \\
\text { Trees }\end{array}$ & Per-cent & $\begin{array}{c}\text { BF } \\
\text { Trees }\end{array}$ & Per-cent & $\begin{array}{c}\text { BF } \\
\text { Trees }\end{array}$ & Per-cent & $\begin{array}{c}\text { BF } \\
\text { Trees }\end{array}$ & Per-cent & $\begin{array}{c}\text { BF } \\
\text { Trees }\end{array}$ & Per-cent & $\begin{array}{c}\text { BF } \\
\text { Trees }\end{array}$ & Per-cent & $\begin{array}{c}\text { BF } \\
\text { Trees }\end{array}$ & Per-cent \\
\hline 1 & 0 & 0 & 0 & 0 & 0 & 0 & 0 & 0 & 0 & 0 & 0 & 0 & 0 & 0 & 0 & 0 \\
\hline 3 & 0 & 0 & 0 & 0 & 0 & 0 & 0 & 0 & 0 & 0 & 0 & 0 & 0 & 0 & 0 & 0 \\
\hline 4 & 0 & 0 & 0 & 0 & 0 & 0 & 0 & 0 & 0 & 0 & 0 & 0 & 0 & 0 & 0 & 0 \\
\hline 5 & 0 & 0 & 0 & 0 & 0 & 0 & 0 & 0 & 0 & 0 & 0 & 0 & 0 & 0 & 0 & 0 \\
\hline 6 & 0 & 0 & 0 & 0 & 0 & 0 & 0 & 0 & 0 & 0 & 0 & 0 & 0 & 0 & 1 & 1.7 \\
\hline 9 & 0 & 0 & 0 & 0 & 0 & 0 & 0 & 0 & 1 & 1.7 & 1 & 1.7 & 2 & 3.3 & 7 & 11.7 \\
\hline 10 & 0 & 0 & 0 & 0 & 0 & 0 & 0 & 0 & 1 & 1.7 & 2 & 3.3 & 3 & 5.0 & 13 & 21.7 \\
\hline 11 & 0 & 0 & 0 & 0 & 0 & 0 & 0 & 0 & 2 & 3.3 & 4 & 6.7 & 6 & 10.0 & 22 & 36.7 \\
\hline 12 & 0 & 0 & 0 & 0 & 0 & 0 & 0 & 0 & 3 & 5.0 & 7 & 11.7 & 10 & 16.7 & 28 & 46.7 \\
\hline 13 & 0 & 0 & 0 & 0 & 0 & 0 & 0 & 0 & 4 & 6.7 & 10 & 16.7 & 14 & 23.3 & 40 & 66.7 \\
\hline 14 & 0 & 0 & 0 & 0 & 0 & 0 & 0 & 0 & 9 & 15.0 & 15 & 25.0 & 17 & 28.3 & 44 & 73.3 \\
\hline 15 & 0 & 0 & 0 & 0 & 0 & 0 & 0 & 0 & 11 & 18.3 & 18 & 30.0 & 20 & 33.3 & 48 & 80.0 \\
\hline
\end{tabular}

\section{Discussion}

In both studies, commercial trees propagated from REO sources resulted in a dramatic reduction in overall incidence and delayed initial appearance of NBF when compared to traditional commercial nursery sources (Figures 2 and 3). In every study, once NBF was identified in a population, its subsequent incidence always increased. As populations approached 100\% affected, the rate of increase would understandably decrease, although no declines were observed in the proportion of affected trees. Greater control was observed for Nonpareil clonal sources than for Carmel when using either REO or traditional commercial sources.

Establishing REO-based foundation-stock is effective in remediating NBF clonal degeneration in almond clones. Clone quality deterioration with age is an inescapable consequence of the immortalization of tree crop genotypes by consecutive, long-term vegetative propagations [2-5]. The mechanisms remain unknown and appear complex, obviating the otherwise promising opportunities for DNA sequence analysis [5,25]. Vegetative progeny testing, while tedious and time-consuming, remains the only reliable strategy for assessing and maintaining clone integrity. For this reason, many commercial tree crop nurseries have depended upon highly-monitored clonal lineages to maintain the integrity of their particular clone-source. This type of sequential propagation from a common well-characterized source also allows intra-clonal selections for traits such as improved productivity that commercial nurseries exploit to distinguish and market their particular clone-sources. Based on this paradigm of maintenance/improvement through intra-clonal sequential selections within unique nursery clone-sources, early nursery efforts to control NBF emphasized selecting individual trees from such established, elite clonal-lineages that were free from symptoms in otherwise highly symptomatic orchard plantings, for use as future 'improved' propagation sources. Nursery propagation lineages were thus analogous to tree growth where sequential tree-branch ramifications represent sequential generations of propagation-wood selection from more recently established orchards (which possessed the shoot vigor required for the large amount of budwood needed commercially).

NBF has been shown to be a disorder that increases both in individual trees as they age $[9,14,26]$ as well as individual propagation lineages $[12,17,18]$. Consequently, just as the lowest NBF incidence and so best propagation source would be expected at the base of the tree, the lowest probability of NBF would be expected at the base of the clonal-lineage, which would be the original seedling tree from which the cultivar was initially selected. The variety Nonpareil resulted from a seedling first grown in the 1860s $[10,27]$ with NBF not being reported until the 1930s despite being extensively 
planted. This indicates that the original seedling tree had a very low probability of NBF that gradually increased with further tree growth as well as increasing generations of propagation from the original seedling-source. Fortunately, by 1960 when Kester [28], initially recognized the relation of NBF with clone aging and, therefore, the potential remediation through propagation from earlier clonal-sources, many northern Sacramento Valley orchards still contained individual Nonpareil trees 100+ years old that were propagated near the time of initial cultivar release. The epicormic buds, ontogenetically, had lower potential for NBF expression than subsequent buds that formed on resulting propagules. Therefore, it is possible that propagation from these buds could restore the original 'normal' phenotype, at least for several years to decades. Returning to these old relic trees for collecting propagation wood thus represents a successful strategy for avoiding NBF.

More than 400,000 ha are currently planted to almonds in California, with over 162,000 ha at 100 to 120 trees per acre, planted to Nonpareil as the dominant variety [11]. (Almond is self-sterile, requiring both early and late season pollenizers to achieve commercial yields). The propagation of the 40,000,000 Nonpareil trees currently in commercial production would have required extensive sequential propagation from multiple propagation lineages, resulting in the variability observed in Table 4. By the time this test orchard was planted in 1990, most commercial nurseries had started to recognize the value of REO propagation sources and begun to shift to these sources, although many were understandably reluctant to abandon their well-established, well-characterized and well-branded propagation lineages. While, Nonpareil clone-source C4, represents a common commercial source prior to 1990, the other commercial sources represent such initial nurseries transition efforts. Based on this and smaller NBF test plots, most modern commercial nursery propagation of Nonpareil is based on the REO FPS sources evaluated in this study (Table 1). The eventual breakdown of Nonpareil clonal-source $\mathrm{C} 4$, a nursery selection from a separate but similar REO source, may indicate a vulnerability unique to that source, or alternatively, that all REO sources may be eroding over the subsequent 40-50 years from the original selection, similar to the erosion that occurred from the original seedling tree until first expression in the 1930s.

Commercial propagation of the Carmel variety from REO sources delayed and diminished NBF expression, although because this is a progressive disorder, all FPS REO clonal-sources showed NBF by year 10. Previous, related studies have shown that this cultivar can still be commercially profitable if NBF is delayed until after development of the key scaffolds and branches making up the basic tree bearing-architecture, which is usually about year 7 [18]. The reduced propagation options for NBF control for Carmel parallel the reduced time from cultivar introduction in 1964 to the first reported incidents of NBF in 1977 [18]. While propagation from the Delta mother tree or even the original Carmel seedling tree should result in further reductions in NBF progeny trees, the number of buds available from these individual trees inherently limits the number of trees possible. At its current acreage of $13 \%$ of the currently planted 400,000 ha almond acres, or 53,000 ha at 100 to 120 trees per acre, the orchard replenishment would require large nursery propagation mother blocks and so inherently multiple propagation cycles from the initial seedling tree. Consequently, while individual REO-based low-NBF propagation sources are available for this cultivar, commercial scale-up is problematic and, as a result, this cultivar has declined from being the second most extensively planted variety in 1990 at almost $30 \%$ of the acreage to only $13 \%$ of the acreage at present [11].

While epicormic meristems have been shown to be valuable sources for the remediation of NBF in almond, the mechanism remains unknown. Epicormic meristems are unique in that they can be very long-lived yet exist at only rudimentary stages of development $[20,21]$. Their morphology and ontogeny also allows them to be arrested at a specific point in development. In contrast, recently-formed axillary meristems normally used in almond propagation are histogenetically complex and need to be regularly renewed.

Basal axillary buds could be the result of recent epicormic shoot initiation and development or could be the consequence of multiple growth-cycles in the often inherently slow-growing lower canopy shoots. Thus, differences between older epicormic and recently-formed axillary bud ontogeny 
is important because the extensive tree hedging currently recommended to suppress clone aging in FPS foundation blocks [14] (Figure 1) tends to push both epicormic and axillary buds for the next generation of propagation budwood collection.

\section{Conclusions}

This study examined NBF development using basal epicormic buds from individual trees of advanced age (REO sources) as an alternative source of propagation stock. Results show the age-related progression of NBF is suppressed in these epicormic meristems, possibly owing to their unique origins and ontogeny. Long-term NBF development in commercial orchards propagated from foundation blocks established from these sources was also dramatically suppressed, even over the 10- to 20-year expected commercial orchard-lifetimes. Thus, REO-based foundation stock was effective in suppressing NBF, an age-related disorder in almond. The extent and so commercial value of this suppression varied with cultivar and was related to NBF expression potential of the initial seedling tree for each cultivar and the time or number of generations of sequential vegetative propagations until NBF first appeared. Because the nature and ontogeny of epicormic meristems are largely uncharacterized for this as well as most tree crops, the underlying mode of action for suppression remains unknown and vegetative-progeny testing remains the only effective strategy for identifying suitable commercial propagation clone-sources.

Author Contributions: Conceptualization, T.G. and B.L.; Methodology, T.G.; Validation, T.G., B.L. and J.E.P.; Formal Analysis, T.G., B.L., J.E.P.; Investigation, T.G., B.L., J.E.P.; Resources, T.G.; Writing-Original Draft Preparation, T.G.; Writing-Review and Editing, T.G., J.E.P., B.L.; Visualization, T.G., J.E.P.; Supervision, T.G.; Project Administration, T.G.; Funding Acquisition, T.G., B.L.

Funding: This research was funded by Almond Board of California and the California Nurseries Advisory Board Funding Number 498B with support from the University of California at Davis.

Acknowledgments: The authors wish to acknowledge support given by Paramount Orchards, Wasco California and Billings Ranch, Delano California in providing fields and land management for these valuations.

Conflicts of Interest: The authors declare no conflict of interest.

\section{References}

1. Janick, J. The Origins of Fruits, Fruit Growing, and Fruit Breeding. Plant Breed. Rev. 2005, 25, $255-320$.

2. Kester, D.E. The clone in Horticulture. HortScience 1983, 18, 831-837.

3. Skowcroft, W.R. Somaclonal Variation, the Myth of Clonal Uniformity. In Genetic Flux in Plants; Hohn, B., Dennis, E.S., Eds.; Springer: New York, NY, USA, 1985; pp. 217-245.

4. Skirvin, R.M.; McPheeters, K.D.; Norton, M. Sources and frequency of somaclonal variation. HortScience 1994, 29, 1232-1237. [CrossRef]

5. D'Aquila, P.; Rose, G.; Bellizzi, D.; Passarino, G. Epigenetics and aging. Maturitas 2013, 74, $130-136$. [CrossRef]

6. Fraga, M.F.; Rodriguez, R.; Canal, M.J. Genomic DNA methylation-demethylation during aging and reinvigoration of Pinus radiata. Tree Physiol. 2002, 22, 813-816. [CrossRef] [PubMed]

7. Kester Dale, E.; Asay, R.N. Variability in noninfectious bud-failure of 'Nonpareil' almond. Location and environment. J. Am. Soc. Hortic. Sci. 1978, 103, 377-382.

8. Kester, D.E.; Jones, R.W. Noninfectious bud-failure from breeding programs of almond (Prunus amygdalus Batsch). J. Am Soc. Hortic. Sci. 1970, 74, 214-219.

9. Fenton, C.A.L.; Kester, D.E.; Kuniyuki, A.H. A model for the development of noninfectious bud failure in vegetatively propagated populations of almond cultivars. Hortscience 1986, 21, 738.

10. Wilson, E.E.; Schein, R.D. The nature and development of noninfectious bud-failure in almond. Hilgardia 1956, 24, 519-542. [CrossRef]

11. Almond Board of California. 2018. Available online: http://www.almonds.com/sites/default/files/Almanac\% 202018.pdf (accessed on 6 January 2019). 
12. Kester, D.E.; Shackel, K.A.; Micke, W.C.; Gradziel, T.M.; Viveros, M. Variability in potential and expression of noninfectious bud-failure among nursery propagules of 'Carmel' almond. Acta Hortic. 1998, 470, 268-272. [CrossRef]

13. Fenton, C.A.L.; Kuniyuki, A.H.; Kester, D.E. Search for a viroid etiology for noninfectious bud failure in almond. HortScience 1988, 23, 1050-1053.

14. Kester, D.E.; Gradziel, T.M. Genetic Disorders. In Almond Production Manual; Micke, W.C., Ed.; University of California: Oakland, CA, USA, 1996; pp. 76-87.

15. Kester, D.E. Noninfectious Bud-Failure in Almond. In Virus Diseases and Disorders of Stone Fruits in North America; Fulton, R.W., Ed.; Agricultural Research Service, U.S. Department of Agriculture: Washington, DC, USA, 1976; pp. 278-283.

16. Kester, D.E. Noninfectious bud-failure, a nontransmissable inherited disorder in almond. I. Pattern of phenotypic inheritance. Proc. Am. Soc. Hortic. Sci. 1968, 92, 7-15.

17. Kester, D.E. Noninfectious bud-failure, a nontransmissable inherited disorder in almond II. Progeny tests for bud-failure. Proc. Am. Soc. Hortic. Sci. 1968, 92, 16-28.

18. Kester, D.E.; Shackel, K.A.; Micke, W.C.; Viveros, M.; Gradziel, T.M. Noninfectious bud failure in 'Carmel' almond, I. Pattern of development in vegetative progeny trees. J. Am. Soc. Hortic. Sci. 2004, 129, 244-249. [CrossRef]

19. Negrón, C.; Contador, L.; Lampinen, B.D.; Metcalf, S.G.; Guédon, Y.; Costes, E.; DeJong, T.M. Differences in proleptic and epicormic shoot structures in relation to water deficit and growth rate in almond trees (Prunus dulcis). Ann Bot. 2014, 113, 545-554. [CrossRef]

20. Fontaine, F.; Kiefer, E.; Clemen, T.C.; Burrus, M.; Druelle, J.L. Ontogeny of the proventitious epicormic buds in Quercus petraea. II. From 6 to 40 years of the tree's life. Trees Struct. Funct. 1999, 14, 83-90.

21. Meier, A.R.; Saunders, M.R.; Michler, C.H. Epicormic buds in trees: A review of bud establishment, development and dormancy release. Tree Physiol. 2012, 32, 565-584. [CrossRef]

22. Preece, J.E. Stock Plant Physiological Factors Affecting Growth and Morphogenesis. In Plant Propagation by Tissue Culture, 3rd ed.; George, E.F., Hall, M.A., de Klerk, G.J., Eds.; Springer: Dordrecht, The Netherlands, 2008; Volume 1, p. 507.

23. Fishel, D.W.; Zaczek, J.J.; Preece, J.E. Positional influence on rooting of shoots forced from the main bole in swamp white oak and northern red oak. Can. J. For. Res. 2003, 33, 705-711. [CrossRef]

24. Foundation Plant Services. 2019. Available online: http://fps.ucdavis.edu/index.cfm (accessed on 6 January 2019).

25. Fresnedo-Ramírez, J.; Chan, H.M.; Parfitt, D.E.; Crisosto, C.H.; Gradziel, T.M. Genome-wide DNA-(de)methylation is associated with Noninfectious Bud-failure exhibition in Almond (Prunus dulcis [Mill.] D.A.Webb). Sci. Rep. 2017, 7. [CrossRef]

26. Kester, D.E. Noninfectious bud-failure, a nontransmissable inherited disorder in almonds, III. Variability in BF potential within plants. J. Am. Soc. Hortic. Sci. 1970, 95, 162-165.

27. Gradziel, T.M. Almond origin and domestication. In Horticultural Reviews; Janick, J., Ed.; John Wiley \& Sons: Hoboken, NJ, USA, 2011; pp. 23-82.

28. Kester, D.E. Inheritance of noninfectious bud-failure in almond. Proc. Am. Soc. Hortic. Sci. 1961, 77, $278-285$.

(C) 2019 by the authors. Licensee MDPI, Basel, Switzerland. This article is an open access article distributed under the terms and conditions of the Creative Commons Attribution (CC BY) license (http://creativecommons.org/licenses/by/4.0/). 